\title{
The Study of Aetiology of Chronic Obstructive Pulmonary Disease (COPD) in Non-Smokers
}

\author{
Nisha Mathew, Zone Xavier, Ashish S Deshmukh*, Hafiz Deshmukh, Sunil Jadhav and Shivaprasad Kasat
}

Department of Pulmonmary Medicine, MGM Medical College, Aurangabad, India

\begin{abstract}
Although COPD occurs predominantly in smokers, non-smokers also develop COPD. In the past decade and especially the past 5 years, results from a growing number of published studies have suggested that risk factors other than smoking are strongly associated with COPD. The aim of the present study is to explore the different causes of non-smoker COPD patients getting treatment from Pulmonary Medicine department and to compare the demographic incidence of COPD in non-smokers in rural \& urban areas.

It's a study of 126 patients who came to pulmonary medicine department with breathlessness and cough. Every patient underwent spirometry and diagnosis of COPD got confirmed by post bronchodilator FEV1/FVC. Detailed history was taken regarding various risk factors leading to COPD, like biomass exposure, environmental tobacco smoke exposure, occupational exposure, outdoor and indoor air pollution, long standing bronchial asthma, history of pulmonary tuberculosis and associated co-morbidities.

In this study we found out that the exposure to biomass smoke is the most common aetiology of non-smoker COPD, followed by environmental tobacco smoke. Females are affected more than males. Non smoker COPD is more common in rural population than urban population.
\end{abstract}

Keywords: Chronic obstructive pulmonary disease; Body mass index; Forced expiratory volume in one second; Forced vital capacity

\section{Introduction}

Chronic Obstructive Pulmonary Disease (COPD) is a common, preventable \& treatable disease, characterized by persistent airflow limitation that is progressive and associated with an enhanced chronic inflammatory response in the airways and in the lungs to noxious particles or gases, exacerbations and co-morbidities contributes to overall severity in individual patients [1].

Chronic obstructive pulmonary disease (COPD) is characterized by progressive airflow obstruction and destruction of lung parenchyma, and is caused by chronic exposure of genetically susceptible individuals to environmental factors. Tobacco smoke, biomass fuel exposure, passive smoking, exposure to indoor and outdoor air pollutants, workplace exposure to dust and fumes, history of repeated lower respiratory tract infections during childhood, history of pulmonary tuberculosis, chronic asthma, intrauterine growth retardation, poor nourishment, and poor socioeconomic status.

About three billion people, half the worldwide population are exposed to smoke from biomass fuel compared with 1.01 billion people who smoke tobacco, suggest exposure to biomass fuel might be the biggest risk factor for COPD globally [2]. Rural women in developing countries bear the largest share of this burden resulting from chronic exposure to biomass fuel smoke. In the Obstructive Lung Disease in North Sweden study [OLIN] study, Lundback et al. found that smokers account for only $45 \%$ of COPD cases among adult aged 46-77yrs. Occupational exposure to dusts, gases, welding fumes, cadmium is associated with increased incidence of COPD of moderate severity [37]. A prior diagnosis of asthma, among women, lower education levels are associated with an increased risk for COPD among never smokers [4]. Passive smoking is considered as a risk factor of COPD [5]. Air pollution is also an aetiological factor in COPD [6].

\section{Materials and Methods}

Testing and evaluation was carried out in all OPD and IPD patients whose symptoms were suggestive of COPD and those who were non- smokers and above the age of 30 yrs. The study was conducted at a tertiary care hospital at MGM Hospital, Aurangabad, Maharashtra, India from August 2012-October 2014.

Clinical diagnosis was considered for patients who had dyspnoea, chronic cough or sputum production, and a history of exposure to risk factors for the disease. Spirometry was done to confirm the diagnosis. The presence of a post-bronchodilator FEV1/FVC $<0.70$ confirms the presence of persistent airflow limitation and thus of COPD. We excluded all patients who were smokers, immune compromised, pregnant ladies, below the age of 30 yrs. Detailed history was taken regarding the condition: Mode of onset, Duration, Progress of the disease, Age of the patient, Sex of the patient, BMI alterations, Education, Status of living, Occupational exposure, Childhood respiratory disease, Indoor/ Outdoor air pollution, History of passive smoking, History of exposure to biomass smoke in years, Family history of Bronchial asthma or Chronic Obstructive Pulmonary Disease, Symptoms first diagnosed, Treatment modalities used, History of Hypertension, Diabetes Mellitus, Tuberculosis, Ischemic heart disease and Stroke.

In case of Biomass Exposure, participants with 6 months or more exposure to biomass fuel:

(1) Cooking using wood,

(2) Cooking using alternatives like coal, crop residues, or dung were questioned. Participants also reported the number of years of

*Corresponding author: Ashish S Deshmukh, Professor and HOD Department of Pulmonmary Medicine, MGM Medical College, Aurangabad, India, Tel: 9545179105; E-mail: hodpulmmgm@gmail.com

Received December 14, 2015; Accepted December 19, 2015; Published December 26,2015

Citation: Mathew N, Xavier Z, Deshmukh AS, Deshmukh H, Jadhav S, et al. (2015) The Study of Aetiology of Chronic Obstructive Pulmonary Disease (COPD) in Non-Smokers. J Pulm Respir Med 5: 304. doi:10.4172/2161-105X.1000304

Copyright: ๑ 2015 Mathew N, et al. This is an open-access article distributed under the terms of the Creative Commons Attribution License, which permits unrestricted use, distribution, and reproduction in any medium, provided the original author and source are credited. 
exposure for each category.

Additional measures evaluated included BMI $\left(\mathrm{kg} / \mathrm{m}^{2}\right)$; total number of years of education; self-reported hospitalization for breathing problems and recurrent respiratory tract infections prior to the age of

10 years.

\section{Observation and Results}

In this study, "Aetiology of COPD in non-smokers", we have taken 126 patients during 2 years 3 months period. Exposure to biomass smoke comprises the major portion in aetiology. The following tables and figures describe distribution of COPD in non-smokers on the basis of sex and different risk factors (Table 1 and Figure 1).

\section{Analysis}

In present study out of 126 patients, $94(74.6 \%)$ were females and $32(25.4 \%)$ were males. Out of 94 females, 46(48.94\%) were from rural, $48(51.06 \%)$ are from urban. Out of 32 males, $18(56.25 \%)$ are from rural, $14(43.75 \%)$ are from urban.

In the above graph the different aetiology of COPD other than smoking are demonstrated. In this study, out of 126 patients, $97(76.98 \%)$ had chulha exposure, 66(52.38\%) had exposure to environmental tobacco smoke, 56(44.44\%) had occupational exposure, 21(16.67\%) had past history of pulmonary tuberculosis, $11(8.73 \%)$ had air pollution exposure, 9(7.14\%) had history of recurrent respiratory tract infections, $8(6.35 \%)$ had history of long standing asthma (Table 2 and Figure 2 ).

\section{Discussion}

The present study shows that exposure to biomass smoke is the most common aetiology of non-smoker COPD. This is in favour with the study conducted by Salvi et al. [2] that exposure to biomass smoke is the biggest risk factor [8]. Previous study by $\mathrm{Hu}$ et al. [9] reported exposure to biomass fuel smoke was found to be associated with a 2.3-

\begin{tabular}{|c|c|c|c|c|c|c|}
\hline Sex & Rural & $\%$ & Urban & $\%$ & Total & $\%$ \\
\hline Female & 46 & 48.94 & 48 & 51.06 & 94 & 74.6 \\
\hline Male & 18 & 56.25 & 14 & 43.75 & 32 & 25.4 \\
\hline Total & $\mathbf{6 4}$ & & $\mathbf{6 2}$ & & $\mathbf{1 2 6}$ & $\mathbf{1 0 0}$ \\
\hline
\end{tabular}

Table 1: Distribution of Non-smoker COPD among males and females.

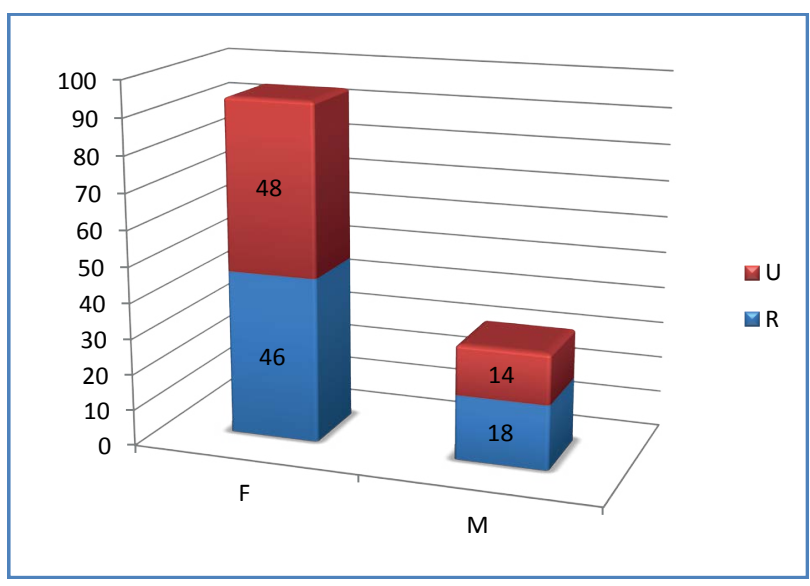

Figure 1: Distribution of Non-smoker COPD according to sex.

\begin{tabular}{|c|c|c|}
\hline Etiology & Frequency & $\%$ \\
\hline Past History of Pulmonary TB & 21 & $16.67 \%$ \\
\hline Recurrent Resp. Tract Infections & 9 & $7.14 \%$ \\
\hline Air Pollution Exposure & 11 & $8.73 \%$ \\
\hline Chulha Exposure & 97 & $76.98 \%$ \\
\hline Passive Smoking & 66 & $52.38 \%$ \\
\hline Long standing Bronchial asthma & 8 & $6.35 \%$ \\
\hline Occupational exposure & 56 & $44 \%$ \\
\hline
\end{tabular}

Table 2: Distribution of non-smoker COPD according to aetiology.

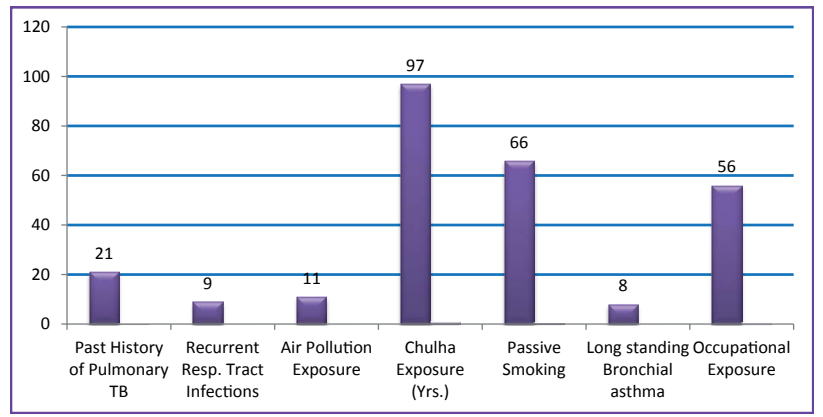

Figure 2: Different aetiology in non-smoker COPD.

fold increased risk of COPD. According to Lopez et al. [10] 3 billion people currently are exposed to biomass smoke worldwide compared with 1.1 billion smokers, it seems likely that exposure to biomass smoke is the biggest risk factor for COPD globally.

Rural women in developing countries bear the largest share of this burden resulting from chronic exposure to biomass fuel smoke. Study conducted by Priscilla Johnson et al. among non-smoking rural females, contributed to this. Our study also shows that COPD is more common among rural population (Figures 1 and 2).

In this study (Figure 1) out of 126 patients, $94(74.6 \%)$ were females and $32(25.4 \%)$ were males. Females were affected more than males. This is supported by the study conducted by Jindal and Behera [9].

Farmers who worked in the fields for a minimum of 20 years developed COPD. It is in favour with a previous study conducted by Lamprecht et al. [11].

Exposure to silica and welding fumes also causes COPD. This is supported by previous studies conducted by Silvana et al. [12] shows that expose to welding fumes may cause COPD.

In this study out of 126 patients, 9 patients had history of recurrent respiratory tract infection in childhood. It supports the previous study by Seif O. Shaheen et al. which shows that history of severe childhood respiratory infection has been associated with reduced lung function and increased respiratory symptoms in adulthood [13]. This study shows that patients who had air pollution exposure in the past developed COPD in their late lives which favours the study conducted by Phillips [14] reported that environmental pollutants were associated with COPD in 1963.

The study also shows patients who had history of pulmonary tuberculosis in the past developed COPD, which is supported by previous studies conducted by Birath et al. [15] and Snider et al. [16]. 
It also shows that passive smoking is a risk factor for development of COPD, out of 126 patients, 66 (52.38\%) gave history of passive smoking. There are only a few cross-sectional and longitudinal studies that have shown ETS exposure as an important risk factor for obstructive lung disease with a significant dose response relationship [17].

In this study, out of 126 patients, 8 (6.4\%) had longstanding and poorly treated bronchial asthma. They developed COPD which favours the previous study by Silva GE et al. Chronic airway inflammation \& airflow obstruction cause lung remodelling from thickening and fibrosis of airway walls and this could result in COPD as supported by a previous report Vignola et al. [18]

Family history is also a risk factor for COPD, independent of family history of smoking, personal life time smoking, or childhood ETS exposure. This is in line with previous study conducted by Hersh et al. [19].

\section{References}

1. http://www.goldcopd.org/uploads/users/files/GOLD_Report_2013_Feb20.pdf

2. Salvi SS, Barnes PJ (2009) Chronic obstructive pulmonary disease in nonsmokers. Lancet 374: 733-743.

3. Cullinan $P$ (2012) Occupation and chronic obstructive pulmonary disease (COPD). Br Med Bull 104: 143-161.

4. Lamprecht B, McBurnie MA, Vollmer WM, Gudmundsson G, Welte T, et al. (2011) COPD in never smokers: results from the population-based burden of obstructive lung disease study. Chest 139: 752-763.

5. Coultas DB (1998) Health effects of passive smoking. 8. Passive smoking and risk of adult asthma and COPD: an update. Thorax 53: 381-387.

6. Lopez AD, Shibuya K, Rao C, Mathers CD, Hansell AL, et al. (2006) Chronic obstructive pulmonary disease: current burden and future projections. Eur Respir J 27: 397-412.

7. Mathers CD, Loncar D (2006) Projections of global mortality and burden of disease from 2002 to 2030 . PLoS Med 3: e442.

8. Behera D, Jindal SK (1991) Respiratory symptoms in Indian women using domestic cooking fuels. Chest 100: 385-388.

9. Hu G, Zhou Y, Tian J, Yao W, Li J, et al. (2010) Risk of COPD from exposure to biomass smoke: a metaanalysis. Chest 138: 20-31.

10. Lopez AD, Mathers CD, Ezatti M, Jamison DT, Murray CJL (2006) Global burden of disease and risk factors. Washington, DC: World Bank.

11. O'Byrne PM, Pedersen S, Busse WW, Tan WC, Chen YZ, et al. (2006) Effects of early intervention with inhaled budesonide on lung function in newly diagnosed asthma. Chest 129: 1478-1485.

12. Bala S, Tabaku A (2010) Chronic obstructive pulmonary disease in iron-steel and ferrochrome industry workers. Cent Eur J Public Health 18: 93-98.

13. Shaheen SO, Barker DJP, Holgate ST (1995) "Do Lower Respiratory Tract Infections in Early Childhood Cause Chronic Obstructive Pulmonary Disease?" American Journal of Respiratory and Critical Care Medicine Vol. 151, Supplement: Infections, Asthma, and COPD: 1649-1652.

14. phillips AM (1963) The Influence Of Environmental Factors In Chronic Bronchitis. J Occup Med 5: 468-475.

15. Birath G, Caro J, Malmberg R, Simonsson BG (1966) Airways obstruction in pulmonary tuberculosis. Scand J Respir Dis 47: 27-36.

16. Snider GL, Doctor L, Demas TA, Shaw AR (1971) Obstructive airway disease in patients with treated pulmonary tuberculosis. Am Rev Respir Dis 103: 625-640.

17. Dayal HH, Khuder S, Sharrar R, Trieff N (1994) Passive smoking in obstructive respiratory disease in an industrialized urban population. Environ Res 65: 161 171.

18. Vignola AM, Kips J, Bousquet $J$ (2000) Tissue remodeling as a feature of persistent asthma. J Allergy Clin Immunol 105: 1041-1053.

19. Hersh CP, Hokanson JE, Lynch DA, Washko GR, Make BJ, et al. (2011) Family history is a risk factor for COPD. Chest 140: 343-350. 